\title{
United States back in space again
}

- Discovery completes perfect flight

- NASA free to look to the future

\section{- International space station agreement signed}

Washington

ON 29 September, the same day that the launch of the space shuttle Discovery marked the return of the United States into space after a forced hiatus of two and a half years, the first steps were taken towards establishing a permanent manned presence in space. At a ceremony in Washington five hours after the launch of Discovery, representatives of all the United States, Europe, Japan and Canada signed an agreement on the joint construction and operation of an international space station.

Discovery climbed smoothly into orbit only an hour and a half after its scheduled lift-off time. Winds at 40,000 feet were unexpectedly light, and the launch was put off until flight controllers were sure the trajectory would not be unduly affected. About 90 seconds before the end of the resumed countdown, an intended halt at 31 seconds was announced because of problems with cabin pressurization, but the difficulty was resolved, the countdown was not interrupted, and the shuttle left the ground at $11 \cdot 37$ a.m. An anxious silence was broken when the solid-fuel boosters were successfully discarded two minutes into the flight, and from then on Discovery sailed into its intended orbit. The main purpose of the mission, deploying the TDRS (Tracking and Data Relay Satellite), was accomplished only six hours after the launch. After release from the shuttle loading bay, TDRS was boosted into a geostationary orbit by its own two-stage rocket. The new satellite joins a similar one launched in 1983 to give the National Aeronautics and Space Administration (NASA) needed capability to communicate between ground and space. Many future orbital facilities, notably the Hubble Space Telescope, will rely on the TDRS system to pass data to Earth.

Discovery glided down to land at Edwards Air Force Base in California, arriving at $9.37 \mathrm{a} . \mathrm{m}$. local time exactly as scheduled. The successful mission leaves NASA free to begin thinking more generally about the future in space.

The space station was first proposed as an element of US plans for space in President Ronald Reagan's 1984 State of the Union address, at which time he also emphasized his desire to seek international collaboration to build it. But although Japan, Canada and several members of the European Space Agency (ESA) expressed immediate interest, negotiations over the past four years have been hampered by disputes over the kind of research, civil or military, that would be conducted on the space station, and by difficulties in establishing a consensus on sharing the costs and allocating use of the facilities. In the intergovernmental agreement signed last week, the participants settled who would provide what parts of the station and agreed to managerial procedures to run it. The United States will build the basic framework, supply living quarters and power resources, furnish its own laboratory, and build an independent polar-orbiting platform that will work in conjunction with

\section{IMAGE UNAVAILABLE FOR COPYRIGHT REASONS}

US return to space - Discovery lifts off from Kennedy Space Center last Thursday morning.

the space station. Canada's contribution is its Mobile Servicing System, a freemoving robotic elaboration of the manipulating arm it has provided for the shuttle. Japan and ESA will each build attached experimental modules, and ESA will also supply two free-flying vehicles for long-term experiments. Each member of the collaboration will get the use of all experimental facilities for an agreed fraction of the time. To put the space station together, each nation is responsible for getting its own pieces into orbit. ESA and Japan intend to use their own systems, the Ariane and $\mathrm{H}-2$ rockets, and would have to compete with everyone else if they wanted to buy flights on the shuttle.
According to Dr Heinz Riesenhuber West German Minister for Research and Technology and also chairman of the ESA ministerial council, the disagreements over the nature of research to be done on the space station were settled by first observing that it would be impossible to formulate definitions of civil and miltary research that all parties could agree on. The essence of the consensus reached is that each nation can do in its own facilites what it wishes, and can deny use of its facilities to other nations only if sensitive research is proposed. Riesenhuber says this agreement does not pretend to provide a foolproof way of solving any disputes that might arise, but establishes an etiquette so that amicable partners can avoid them. A good contract, he said, is one which once signed "need never be read again". Only nine of the thirteen ESA members are taking part in the space station programme, but according to Reimar Lüst, ESA's director-general, the non-participation of the others was not a sign of dissatisfaction with the terms, because all thirteen had to approve ESA's role as participating agency for the nine.

David Lindley

Shinichiro Ogura, space station chief at the Science and Technology agency, says that Japanese requirements that the space station should be a purely civil venture have also been met. Beyond its interest in microgravity research and Earth observation programmes, Japan sees its participation as a way to learn about and contribute to space technology. Japan has done little in space so far, but there is talk of an ambitious programme stretching into the next century, including a Japanese shuttle (Nature 327, 645; 1987). Although in the present climate the prospect of Japan gaining access to US expertise might have been expected to cause friction, Margaret Finarelli, policy director in the Office of Space Station at NASA, says this was not an issue in negotiations. The different modules will be plugged together in a 'clean' way, she says, and the construction of the various modules will be entirely in the hands of their owners. In hardware alone, the space station will cost the United States \$16 thousand million, with ESA, Japan and Canada putting in four, two and one thousand million dollars respectively. Some 20 shuttle launches will be needed, at perhaps $\$ 100$ million each, for the US sections alone. Both Finarelli and Riesenhuber expressed the hope that, with an international agreement to honour, the US Congress would be under some pressure to keep the money flowing from one yearly budget to the next.

David Lindley \& David Swinbanks 